\title{
Physicochemical and microscopic characterization of implant-abutment joints
}

\author{
Patricia A. Lopes ${ }^{1}$, Adriana F. P. Carreiro ${ }^{1}$, Rubens M. Nascimento ${ }^{2}$,Brendan R. Vahey ${ }^{3}$, \\ Bruno Henriques ${ }^{4}$, Júlio C. M. Souza ${ }^{4}$
}

Correspondence: Dr. Júlio C. M. Souza

Email: jsouza@dem.uminho.pt

\begin{abstract}
'Department of Dentistry, Federal University of Rio Grande do Norte, Natal, RN, Brazil, ${ }^{2}$ Department of Materials Engineering, Federal University of Rio Grande do Norte, Natal, RN, Brazil, ${ }^{3}$ The Herman Ostrow School of Dentistry, University of Southern California, Los Angeles, CA, USA, ${ }^{4}$ Center for Microelectromechanical Systems (CMEMS MINHO), University of Minho, Guimarães, Portugal
\end{abstract}

\section{ABSTRACT}

Objective: The purpose of this study was to investigate Morse taper implant-abutment joints by chemical, mechanical, and microscopic analysis. Materials and Methods: Surfaces of 10 Morse taper implants and the correlated abutments were inspected by field emission gun-scanning electron microscopy (FEG-SEM) before connection. The implant-abutment connections were tightened at $32 \mathrm{Ncm}$. For microgap evaluation by FEG-SEM, the systems were embedded in epoxy resin and cross-sectioned at a perpendicular plane of the implant-abutment joint. Furthermore, nanoindentation tests and chemical analysis were performed at the implant-abutment joints. Statistics: Results were statistically analyzed via one-way analysis of variance, with a significance level of $P<0.05$. Results: Defects were noticed on different areas of the abutment surfaces. The minimum and maximum size of microgaps ranged from $0.5 \mu \mathrm{m}$ up to $5.6 \mu \mathrm{m}$. Furthermore, defects were detected throughout the implant-abutment joint that can, ultimately, affect the microgap size after connection. Nanoindentation tests revealed a higher hardness $(4.2 \pm 0.4 \mathrm{GPa})$ for abutment composed of Ti6Al4V alloy when compared to implant composed of commercially pure Grade 4 titanium $(3.2 \pm 0.4 \mathrm{GPa})$. Conclusions: Surface defects produced during the machining of both implants and abutments can increase the size of microgaps and promote a misfit of implant-abutment joints. In addition, the mismatch in mechanical properties between abutment and implant can promote the wear of surfaces, affecting the size of microgaps and consequently the performance of the joints during mastication.

Key words: Dental implants, implant-abutment, microgaps

\section{INTRODUCTION}

The long-term success of dental implants is widely determined by the integration of the bone-implant interface commonly known as osseointegration. ${ }^{[1-7]}$ Nevertheless, inflammation and bone resorption can occur over the performance of the implant in the oral cavity. Such resorption of bone surrounding the

\begin{tabular}{|l|l|}
\hline \multicolumn{3}{|c|}{ Access this article online } \\
\hline Quick Response Code: \\
\hline
\end{tabular}

implant is defined as peri-implantitis and is likely associated with a biofilm containing pathogenic species. ${ }^{[4,6]}$ Localized inflammatory response of the bone and periodontal tissues observed in peri-implantitis has also been attributed to titanium

This is an open access article distributed under the terms of the Creative Commons Attribution-NonCommercial-ShareAlike 3.0 License, which allows others to remix, tweak, and build upon the work non-commercially, as long as the author is credited and the new creations are licensed under the identical terms.

For reprints contact: reprints@medknow.com

How to cite this article: Lopes PA, Carreiro AF, Nascimento RM, Vahey BR, Henriques B, Souza JC. Physicochemical and microscopic characterization of implant-abutment joints. Eur J Dent 2018;12:100-4. DOI: 10.4103/ejd.ejd_3_17 
degradation and release of metallic ions due to wear, fatigue, and corrosion at the implant-abutment surface connection. ${ }^{[4-6]}$

Previous studies reported on the variation of topographic characteristics within the same implant-abutment assembly such as scratches or plastic deformation on the surfaces of abutment and inner implant connection areas. ${ }^{[5,10]}$ In fact, those defects can increase the size of microgaps within the implant-abutment connection. ${ }^{[7-9]}$ Failures have been associated with the presence of microgaps even though there is no threshold in the microgap size to initiate a failure ${ }^{[5,10]}$ A previous study ${ }^{[4]}$ reported microgaps' sizes ranging from $2 \mu \mathrm{m}$ up to $7 \mu \mathrm{m}$ at implant-abutment joints, while another one reported a variation of microgap size ranging from $10 \mu \mathrm{m}$ up to $1.72 \mathrm{~mm} \cdot{ }^{[10]}$ In addition, studies have reported the effect of casting procedures on the rotational misfit/microgap between the external hexagonal implant and the internal hexagonal abutment. ${ }^{[11]}$ Following screw tightening, a lateral force of $160 \mathrm{~g}$ was applied. A rotational misfit was noted in degrees between the hexagon implant and abutment for all abutment types tested, with a minimum mean value of 1.21 degrees for machined titanium abutments and a maximum mean value of 2.79 degrees for cast $\mathrm{Co}-\mathrm{Cr}^{[11]}$ The microgap size existing at abutments and abutments cast in base metal alloys has also been studied. That study noted the mean marginal microgaps for cast abutments $-15.48 \mathrm{~mm}$ for $\mathrm{Ni}-\mathrm{Cr}, 14.06 \mathrm{~mm}$ for $\mathrm{Co}-\mathrm{Cr}$, and $12.38 \mathrm{~mm}$ for Grade 4 titanium - versus those for milled abutments $-7.51 \mathrm{~mm}$ for Ti6Al4V, $13.51 \mathrm{~mm}$ for stainless steel, and $0.75 \mathrm{~mm}$ for gold. ${ }^{[12]}$

The growth of biofilms in the implant-abutment joint microgaps can lead to peri-implant inflammations and consequent bone loss. ${ }^{[13,14]}$ In addition, the corrosion of structural materials at the connections can occur due to the retention of acidic oral fluids gathered from dietary and microbial metabolism. ${ }^{[6,15]}$ Previous studies have reported on the decrease of corrosion resistance of titanium in the presence of biofilms. ${ }^{[15]}$ Considering the mechanical aspect, micromovements resulting from occlusal loads during mastication can lead to wear of contacting materials in the connection area, thus increasing the microgap sizes. ${ }^{[3,16]}$ Occlusal loads are distributed through the microgaps promoting sliding micromovements under variable displacement that also affect the mechanical integrity of the abutment screw. These micromovements found within the microgaps can lead to unscrewing and later failure of the implant-supported prosthesis. ${ }^{[3,5,8,17,18]}$
There are many dental implant systems routinely presented in the commercial market that should be investigated considering the chemical composition, mechanical properties, topographic characteristics, processing method, and connection design. ${ }^{[5]}$ Thus, the objective of the present study was to analyze the surfaces of Morse taper abutment and inner implant connections as well as implant-abutment microgaps by microscopic, chemical, and mechanical analyses.

\section{MATERIALS AND METHODS}

\section{Chemical and microscopic analyses of implant- abutment systems}

Ten Titamax Morse taper implants (Neodent ${ }^{\circledR}$; Curitiba/Brazil) with $3.75 \mathrm{~mm}$ diameter and $11 \mathrm{~mm}$ length were assessed in this study. The topography of the abutment, abutment screw, and implant connection area was inspected by scanning electron microscopy (SEM, Shimadzu SS-550, Japan) on secondary electrons mode.

Then, implants were coupled to a metallic holding device in order to connect the abutments to the implants by applying a torque of $32 \mathrm{Ncm}$. A handheld torque meter (Neodent ${ }^{\circledR}$; Curitiba/Brazil) was used to connect the implant-abutment systems. The implant-abutment assemblies were embedded in epoxy resin and cross-sectioned perpendicularly to the plane of the joint. Cross-section was carried out perpendicularly to the plane of the joint by wet-grinding down to 1200 Mesh and polishing under colloidal silica solution (particle size at $0.04 \mu \mathrm{m}$ ). Different cross-sectioned areas were inspected using a field emission gun-SEM (FEG-SEM, FEI SEM 200; USA) at high magnification. Furthermore, chemical analyses were carried out using energy dispersive spectroscopy (EDS) (EDAX, Pegasus X 4M; USA) coupled to FEG-SEM. The microgap sizes within the implant-abutment connection were measured at ten different zones of each system.

\section{Mechanical characterization by nanoindentation}

Nano-hardness and elastic modulus of the fiveimplantabutment joints were evaluated by nanoindentation tests using a Micro Materials Nano Tester (Nano Instruments, Inc., Knoxville, TN, USA). A Berkovich pyramid tip (apex angle of 143 degrees) was used to perform the nanoindentation measurement by varying the position of the indenter (Berkovich tip) along the implant-abutment cross-section. A load of $20 \mathrm{~N}$ was applied on the surfaces for $15 \mathrm{~s}$ during nanoindentation tests. 


\section{Statistical analysis}

The results were statistically analyzed via one-way analysis of variance, with a significance level of $P<0.05$.

\section{RESULTS}

SEM images of the connection area of the implant and abutments are shown in Figure 1. Inner surfaces of the implant connection revealed defects that can negatively affect the connection to abutments (Figure 1a). Outer and rougher surfaces present high roughness to perform osseointegration as expected. Defects at about $40 \mu \mathrm{m}$ in length in width were noticed on all the abutment surfaces including the surfaces of the connection area (Figure 1c). EDS spectra obtained by chemical analysis of the abutment and implants are shown in Figure 2.

EDS spectra obtained by chemical analysis of the implant showed only "Ti" denoting a structure composed of commercially pure titanium (Figure 2a). However, EDS spectra obtained by chemical analysis on abutment shown in Figure $2 b$ revealed the presence of "Ti," "Al," and "V" that suggests a structure composed of Ti6Al4V alloy. At the implant-abutment joint,
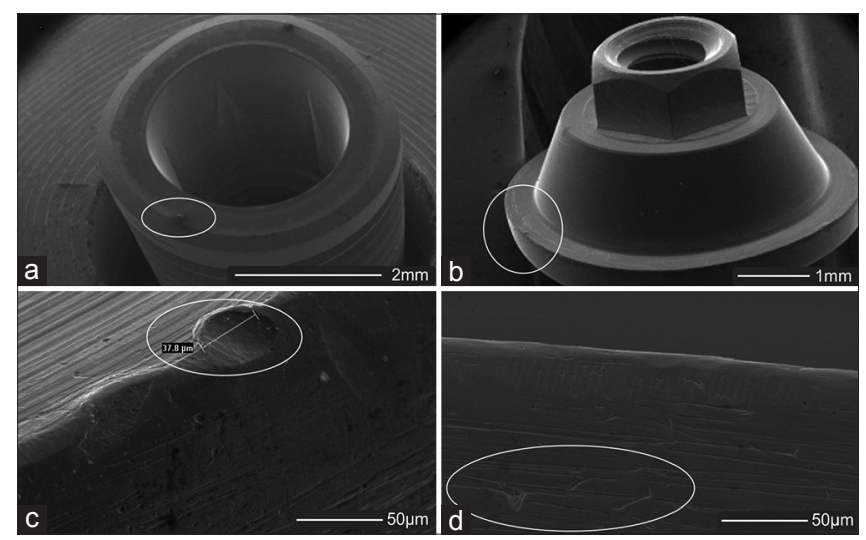

Figure 1: Images obtained by scanning electron microscopy: (a) Implant, (b) abutment; (c and d) marginal area of abutment (secondary electron mode at $15-20 \mathrm{kV}$ ) nano-hardness mean values recorded on abutments were at $4.2 \pm 0.4 \mathrm{GPa}$, while nanohardness mean values for implants were at $3.2 \pm 0.4 \mathrm{GPa}$. As well, the elastic modulus of abutment was higher $(165 \pm 12$ $\mathrm{GPa})$ than that detected for implants $(136 \pm 9 \mathrm{GPa})$.

As shown in Figure 3, microgaps with different sizes were noticed at the implant-abutment connection area. The mean value of microgap sizes was at $2.5 \pm 1 \mu \mathrm{m}$, although the microgap size ranged from 0.5 to $5.6 \mu \mathrm{m}$. The size distribution of microgaps for each system is shown in Figure 4.

\section{DISCUSSION}

In this study, defects noticed on the surface of abutments likely originated from the machining process. In fact, the machining process is susceptible to usual defects; thus, the quality control of all implant brand systems must be considered. In literature, late failures in dental implant systems were associated with the presence of defects at the implant-abutment joint joint. ${ }^{[14,18,19]}$ Defects found on both surfaces can promote a misfit between the implant and abutment connection as well as increase the wear of the structural materials at the sliding contact due to the micromovements generated from mastication loads. ${ }^{[15]}$

As a result of the implant-abutment misfit, the size of microgaps between abutment and implant can vary depending on the mechanical integrity of the implantabutment assembly. Microgap sizes of the Morse taper connection at the implant-abutment joints measured in the present study ranged from 0.5 to $4.6 \mu \mathrm{m}$. Three previous studies reported the size of microgaps at the implant-abutment joints as follows: $0.75-15.48 \mathrm{~mm},{ }^{[12]}$ 2-7 $\mu \mathrm{m},{ }^{[4]}$ and $10-172 \mu \mathrm{m} .{ }^{[10]}$ In addition, one study noted a rotational microgap component in degrees between abutment and implant hex from 1.21 to 2.79 degrees. ${ }^{[11]}$

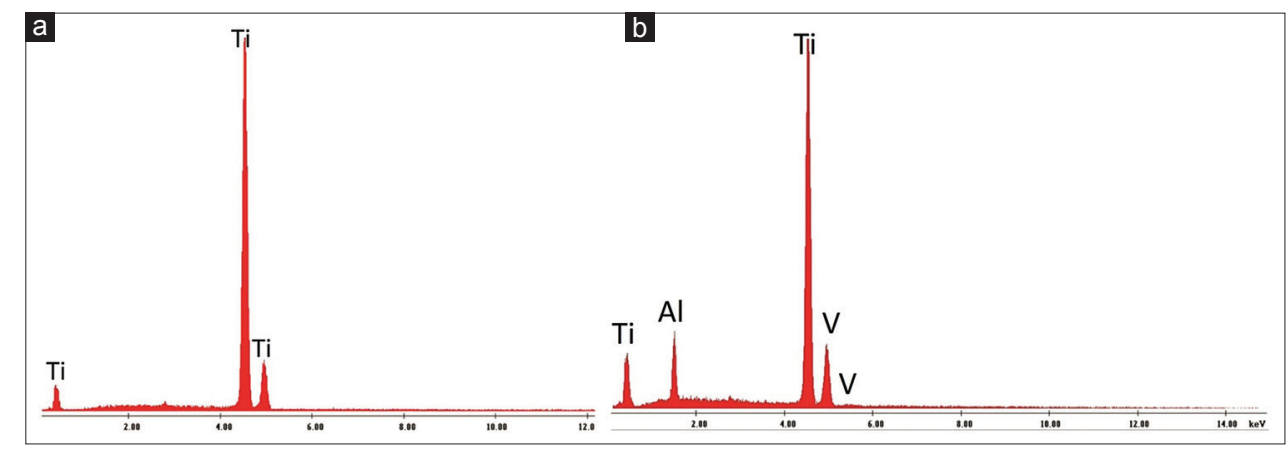

Figure 2: Energy dispersive spectroscopy spectra obtained by chemical analysis of (a) implant and (b) abutment 


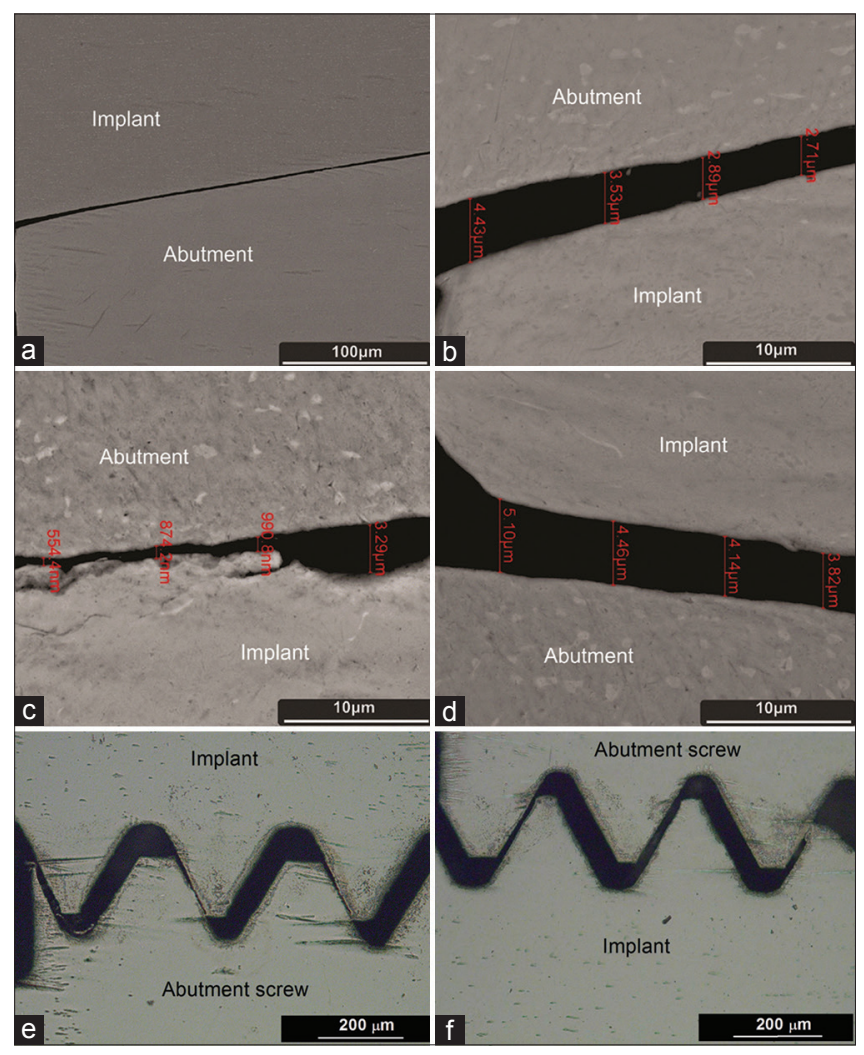

Figure 3: Images of implant-abutment joints obtained by field emission gun-scanning electron microscopy (backscattered electron detector mode at $15 \mathrm{kV}$ ) after vertical cross-section. (a-d) Implant-abutment contacting surfaces. (e-f) Contacting surfaces of the abutment screw and inner implant

The size of microgaps is extremely important for the long-term performance of dental implants and the associated prosthetic success within the oral cavity. For example, a bacterial examination of two Gram-negative species associated with oral biofilms, Pseudomonas aeruginosa and Aggregatibacter actinomycetemcomitans, has shown an average bacteria diameter of around $0.5 \mu \mathrm{m} .{ }^{[20]}$ Microgaps facilitate the accumulation of biofilm and acidic substances across the connection areas. Furthermore, microgaps are stress concentration zones that can induce mechanical failures under regular occlusal loads. ${ }^{[9,14]}$

During occlusal contact, overloads can be transmitted to the bone due to an abrupt distribution of loads through the structural materials of the implantabutment joint. That is increased by a mismatch in physical-mechanical properties between structural materials as well as by the presence of microgaps. ${ }^{[21-24]}$ For instance, Ti6Al4V alloys have a high mechanical strength (tensile strength around 800-900 $\mathrm{MPa}$ ) to act as a prosthetic support associated with higher elastic modulus (approximately 150 GPa) compared to that of commercially pure

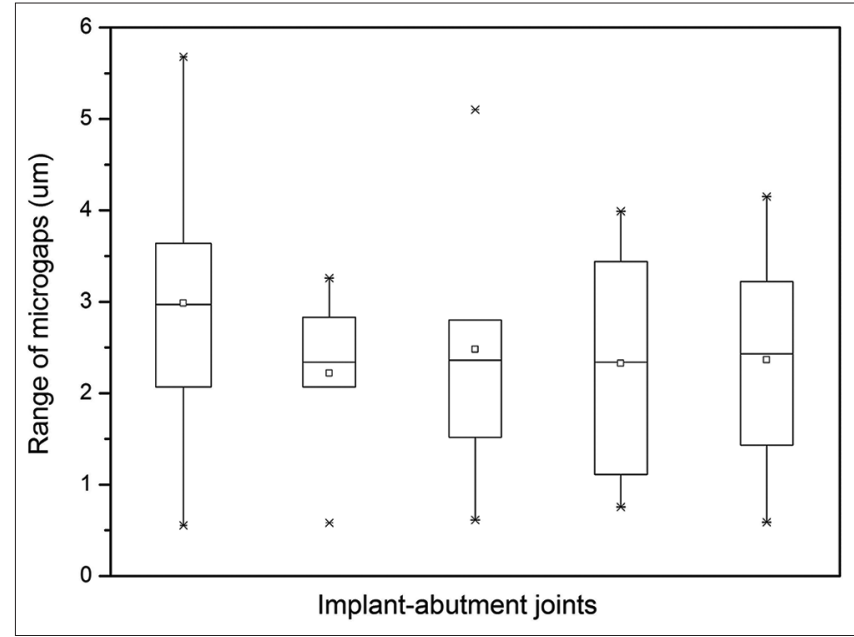

Figure 4: Distribution of microgap sizes for each implant-abutment joint evaluated

titanium (100-110 GPa). ${ }^{[25-27]}$ Finally, the bone has the significant lowest elastic modulus at around 10-19 GPa. ${ }^{[28]}$ The match of elastic modulus would promote a slight distribution of stresses along the implant-abutment joint up to the bone interface, and a similar elastic deformation of structural materials during mastication. ${ }^{[24]}$

The Vicker's hardness values of commercially pure titanium ranged from 160 to $300 \mathrm{HV}$ compared to hardness values at $350-430$ for Ti6Al4V alloys. ${ }^{[24]}$ In our study, values of hardness and elastic modulus for Ti6Al4V and commercially pure titanium were close to those found in literature. However, the variance in hardness between the titanium alloy abutment and the commercially pure titanium dental implant can provoke the wear of the inner implant connection surfaces during torque application to connect the structures or even during micromovements generated from mastication. ${ }^{[6,27,29]}$ On the cortical bone having a Vicker's hardness of around 43-76 HV, an additional concern is likely associated with overloads and mismatch between the hardness of titanium-based structures and the bone surrounding the implant.

Several previous studies reported the high corrosion resistance of titanium and its alloys associated with the presence of a compact titanium oxide $\left(\mathrm{TiO}_{2}\right)$ film formed on their surfaces. ${ }^{[8,18,25,27-30]}$ Notwithstanding, galvanic corrosion takes place when implant and abutment having different chemical composition are in contact and surrounded by an electrolyte solution like a saliva. In literature, a lower galvanic corrosion resistance was noticed for a system composed of $\mathrm{Co}-\mathrm{Cr}$ abutment and commercially pure titanium implant compared to that for titanium-titanium 
joint. ${ }^{[31]}$ In addition, the simultaneous wear and corrosion process occurs when the contacting surfaces between implant and abutments are under sliding micromovements surrounded by saliva and acidic substances from dietary or biofilm metabolism. The degradation of implant-abutment joints can increase their microgap sizes and promote consequent failures. . $^{[1,18,21,31]}$

\section{CONCLUSIONS}

Defects were noticed on all the implant and abutment samples inspected by SEM. Such defects can affect negatively the internal connection of the implant-abutment joints increasing the sizes of microgaps. The results pointed out for the need of improvement in quality control during industrial processing of implant and abutments in order to decrease the number of defects on surfaces. In addition, the sizes of microgaps measured at the implantabutment joints ranged from 0.5 to $5.6 \mu \mathrm{m}$ that can allow the penetration of oral fluids and microorganisms stimulating the corrosion of materials and peri-implant inflammations. In addition, the mismatch in physicalmechanical properties between abutment and implant can lead to wear of the internal connection of implant with increase of microgaps and consequent late failures.

\section{Financial support and sponsorship}

The authors acknowledge the Brazilian funding provided by CAPES and CNPq.

\section{Conflicts of interest}

There are no conflicts of interest.

\section{REFERENCES}

1. Byrne D, Houston F, Cleary R, Claffey N. The fit of cast and premachined implant abutments. J Prosthet Dent 1998;80:184-92.

2. Lima EM, Silva WJ, Moura JS, Faot F, Del Bel Cury AA. Evaluation of surface characteristics of Ti-6Al-4V and Tilite alloys used for implant abutments. Braz Oral Res 2006;20:307-11

3. Hanawa T. Biofunctionalization of titanium for dental implant. Jpn Dent Sci Rev 2010;46:93-101.

4. Piattelli A, Scarano A, Paolantonio M, Assenza B, Leghissa GC, Di Bonaventura G, et al. Fluids and microbial penetration in the internal part of cement-retained versus screw-retained implant-abutment connections. J Periodontol 2001;72:1146-50.

5. Tsuge T, Hagiwara Y, Matsumura H. Marginal fit and microgaps of implant-abutment interface with internal anti-rotation configuration. Dent Mater J 2008;27:29-34.

6. Pereira J, Morsch CS, Henriques B, Nascimento RM, Benfatti CA, Silva FS, et al. Removal torque and biofilm accumulation at two dental implant-abutment joints after fatigue. Int J Oral Maxillofac Implants 2016;31:813-9.

7. Mish CE. Dental Implant Prosthetics. St. Louis: Mosby; 2005.

8. Vieira AC, Ribeiro AR, Rocha LA, Celis JP. Influence of $\mathrm{pH}$ and corrosion inhibitors on the tribocorrosion of titanium in artificial saliva. Wear 2006;261:994-1001.

9. Scarano A, Assenza B, Piattelli M, Iezzi G, Leghissa GC, Quaranta A, et al. A 16-year study of the microgap between 272 human titanium implants and their abutments. J Oral Implantol 2005;31:269-75.

10. Hermann JS, Schoolfield JD, Schenk RK, Buser D, Cochran DL. Influence of the size of the microgap on crestal bone changes around titanium implants. A histometric evaluation of unloaded non-submerged implants in the canine mandible. J Periodontol 2001;72:1372-83.

11. Kano SC, Binon PP, Bonfante G, Curtis DA. The effect of casting procedures on rotational misfit in castable abutments. Int J Oral Maxillofac Implants 2007;22:575-9.

12. Lalithamma JJ, Mallan SA, Murukan PA, Zarina R. A comparative study on microgap of premade abutments and abutments cast in base metal alloys. J Oral Implantol 2014;40:239-49.

13. Broggini N, McManus LM, Hermann JS, Medina RU, Oates TW, Schenk RK, et al. Persistent acute inflammation at the implant-abutment interface. J Dent Res 2003;82:232-7.

14. Broggini N, McManus LM, Hermann JS, Medina R, Schenk RK, Buser D, et al. Peri-implant inflammation defined by the implant-abutment interface. J Dent Res 2006;85:473-8.

15. Souza JC, Henriques M, Oliveira R, Teughels W, Celis JP, Rocha LA, et al. Do oral biofilms influence the wear and corrosion behavior of titanium? Biofouling 2010;26:471-8.

16. Zupnik J, Kim SW, Ravens D, Karimbux N, Guze K. Factors associated with dental implant survival: A 4-year retrospective analysis. J Periodontol 2011;82:1390-5.

17. Binon PP. The effect of implant/abutment hexagonal misfit on screw joint stability. Int J Prosthodont 1996;9:149-60.

18. Souza JC, Henriques M, Oliveira R, Teughels W, Celis JP, Rocha LA, et al. Biofilms inducing ultra-low friction on titanium. J Dent Res 2010;89:1470-5.

19. Heckmann SM, Linke JJ, Graef F, Foitzik Ch, Wichmann MG, Weber HP, et al. Stress and inflammation as a detrimental combination for peri-implant bone loss. J Dent Res 2006;85:711-6.

20. Assenza B, Tripodi D, Scarano A, Perrotti V, Piattelli A, Iezzi G, et al. Bacterial leakage in implants with different implant-abutment 57 connections: An in vitro study. J Periodontol 2012;83:491-7.

21. Hermann JS, Schoolfield JD, Schenk RK, Buser D, Cochran DL. Influence of the size of the microgap on crestal bone changes around titanium implants. A histometric evaluation of unloaded non-submerged implants in the canine mandible. J Periodontol 2001;72:1372-83.

22. Proff P, Steinmetz I, Bayerlein T, Dietze S, Fanghänel J, Gedrange T, et al. Bacterial colonisation of interior implant threads with and without sealing. Folia Morphol (Warsz) 2006;65:75-7.

23. Baggi L, Cappelloni I, Di Girolamo M, Maceri F, Vairo G. The influence of implant diameter and length on stress distribution of osseointegrated implants related to crestal bone geometry: A three-dimensional finite element analysis. J Prosthet Dent 2008;100:422-31.

24. Anusavice KJ. Mechanical properties of dental materials. In: Philip's Science of Dental Materials. 11 ${ }^{\text {th }}$ ed. St. Louis: WB Saunders; 2003. p. 715-36.

25. Souza JCM, Barbosa SL, Ariza EA, Henriques M, Teughels W, Ponthiaux $\mathrm{P}$, et al. How do titanium and Ti6Al4V corrode in fluoridated medium as found in the oral cavity? An in vitro study. Mater Scie Eng 2015;47:384-93.

26. Niinomi M. Recent research and development in titanium alloys for biomedical applications and healthcare goods. Sci Technol Adv Mater 2003;4:445-54.

27. Souza JCM, Henriques M, Teughels W, Ponthiaux P, Celis JP, Rocha LA. Wear and Corrosion Interactions on Titanium in Oral Environment: Literature Review. J Bio Tribo-Cor 2015;1:13.

28. McGlumphy EA, Mendel DA, Holloway JA. Implant screw mechanics. Dent Clin North Am 1998;42:71-89.

29. Noronha Oliveira M, Schunemann WVH, Mathew MT, Henriques B, Magini RS, Teughels W, et al. Can degradation products released from dental implants affect peri-implant tissues? J Period Res 2017. [In press].

30. Zysset PK, Guo XE, Hoffler CE, Moore KE, Goldstein SA. Elastic modulus and hardness of cortical and trabecular bone lamellae measured by nanoindentation in the human femur. J Biomech 1999;32:1005-12.

31. Oh KT, Kim KN. Electrochemical properties of suprastructures galvanically coupled to a titanium implant. J Biomed Mater Res B Appl Biomater 2004;17. 